\title{
DESIGN AND DEVELOPMENT OF ARSENIC AND IRON REMOVAL UNIT FOR DRINKING WATER: A Sustainable Approach in ENVIRONMENT
}

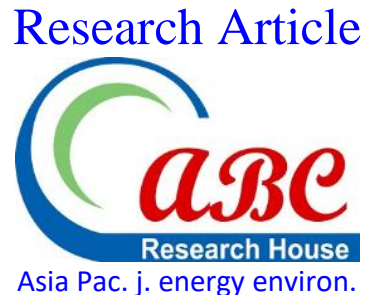

Tangina Akhter ${ }^{1}$, Md. Zainul Abedin ${ }^{2}$, Jayanta Kumar Basak ${ }^{3}$, Farzana Akhter ${ }^{4}$

${ }^{1}$ Assistant Engineer, Bangladesh Agricultural Development Corporation (BADC), Dhaka, BANGLADESH

${ }^{2}$ Professor, Department of Farm Structure, BAU, Mymensingh, BANGLADESH

${ }^{3}$ Assistant Professor, Department of Environmental Science and Disaster Management, Noakhali Science and Technology University, Noakhali3814, BANGLADESH

${ }^{4}$ Scientific Officer, Bangladesh Agricultural Research Institute (BARI), Gazipur, BANGLADESH

*Email for Correspondence: basak.jkb@gmail.com

Abstract

This study elucidated and attempted to design and development of arsenic and iron removal unit for drinking water. The process of reducing iron and arsenic from water has been experimented by developing a unit in the Department of Farm Structure at Bangladesh Agriculture University, Mymensingh. In order to test the performance of the developed unit, arsenic contaminated water with four different concentrations like $0.05,0.10,0.15$ and $0.20 \mathrm{mg} / 1$ were prepared in the laboratory and passed into the developed unit and the respective output concentrations were found to be 0.00 , $0.01,0.025$ and $0.05 \mathrm{mg} / \mathrm{l}$. The input and output concentrations of arsenic were tested in the chemical testing laboratory under the Bangladesh Institute of Nuclear Agriculture, Mymensingh. Iron contaminated water were collected from four selected tube wells of local Mymensingh and were also passed into the developed unit with four input concentrations like $0.18,0.1532,0.179$ and $0.133 \mathrm{mg} / 1$ and the respective output concentrations were found to be $0.10,0.1021,0.11$ and $0.09 \mathrm{mg} / 1$. The concentrations of Iron were tested in the chemical testing laboratory under the Soil Resource Development Institute, Dhaka. The results have revealed that iron and arsenic content brings to allowable limit. The developed unit has the capacity to remove Arsenic and Iron and help to eradicates hazardous problem of people.

Key words

Arsenic, Iron, Removal unit, Bangladesh

This article is is licensed under a Creative Commons Attribution-NonCommercial 4.0 International License.

Attribution-NonCommercial (CC BY-NC) license lets others remix, tweak, and build upon work non-commercially, and although the new works must also

acknowledge \& be non-commercial.

\section{INTRODUCTION}

Arsenic presents in water mainly two forms, organic and inorganic. Organic arsenic is generally fewer toxins than inorganic arsenic. Arsenic in element form is insoluble in water. It is soluble in oxidize form. Inorganic arsenic has been recognized as a human poison since a long times. Oral intake of arsenic has roved to be deadly on many occasions (Zaman et al., 1999; Khan and Ahmad, 1997; Anawas et al., 2002; Khan, 1993). Arsenic is an odorless and tasteless semi metal that occurs naturally in rock and soil, whereas iron in water is a lustrous, ductile, malleable, silver-gray metal (group VIII of the periodic table). It is known to exist in four distinct crystalline forms. Iron rusts in dump air, but not in dry air. It dissolves readily in dilute acids. Iron is chemically active and forms two major series of chemical compounds, the bivalent iron (II), or ferrous, compounds and the trivalent iron (III), or ferric, compounds.

Arsenic is stable in dry air, but the surface oxidizes slowly in moist air to give a bronze tarnish and finally a black covering to the element. When heated in air, arsenic ignites "arsenic trioxide" - actually tetraarsenic hexaoxide, As4 $\mathrm{O}_{6}$. This is accompanied by phosphorescence under some conditions (Pierce and Moore, 1982). When heated in oxygen, arsenic ignites in oxygen to form "arsenic pentoxide" - actually tetraarsenic decaoxide, $\mathrm{As}_{4} \mathrm{O}_{10}$, and $\mathrm{As}_{4} \mathrm{O}_{6}$.

$4 \mathrm{As}(\mathrm{s})+5 \mathrm{O}_{2}(\mathrm{~g}) \rightarrow \mathrm{As}_{4} \mathrm{O}_{10}(\mathrm{~s})$

$4 \mathrm{As}(\mathrm{s})+3 \mathrm{O}_{2}(\mathrm{~g}) \rightarrow \mathrm{As}_{4} \mathrm{O}_{6}(\mathrm{~s})$ 
Iron does not clearly alter in pure water or in dry air, but when both water and oxygen are present (moist air), iron corrodes. Its silvery color changes to a reddish-brown, because hydrated oxides are formed. Dissolved electrolytes accelerate the reaction mechanism, which is as follows:

$4 \mathrm{Fe}+3 \mathrm{O}_{2}+6 \mathrm{H}_{2} \mathrm{O}>4 \mathrm{Fe}^{3+}+12 \mathrm{OH}^{-*}>4 \mathrm{Fe}(\mathrm{OH})_{3}$

or

$4 \mathrm{Fe}(\mathrm{OH})+4 \mathrm{H}_{2} \mathrm{O}$

Usually the oxide layer does not protect iron from further corrosion, but is removed so more metal oxides can be formed. Electrolytes are mostly iron (II) sulphate, which forms during corrosion by atmospheric $\mathrm{SO}_{2}$. In sea regions atmospheric salt particles may play an important role in this process. Iron (II) hydroxide often precipitates in natural waters.

The problem of arsenic contamination was discovered in the early nineties in Bangladesh, whereas it was first confirmed in 1993 in the Chapai Nawabgonj district (Allan et al., 2001). Concentration of As in ground water from the affected area have very large range from $<0.05$ to 2500 micro gram/1 in Bangladesh (WHO, 1978 and WHO, 1993). Moreover it is also found that the contamination of arsenic also changed by the depth of groundwater level and it is higher in shallow aquifers than the deep. Arsenic is mostly found in high concentration in the depth between 9 to $30 \mathrm{~m}$ (BGS, 1999). On the other hand ground water from depth of more than 150 to $200 \mathrm{~m}$ might be arsenic free (BGS, 2000). One of the main reasons beyond the fact is that due to such changes in hydrologic regime and the subsequent oxidation-reduction cycle, chemical degradation of arsenic containing minerals might have taken place and it has been released in the ground water (Karim, 2000).

After being aware of deadly disease arsenic poisoning, millions of men, women and children living in the arsenicaffected areas of the country's 59 districts out of 64 have been fighting to conquer the ongoing battle against the 'arsenic curse' (Karim, 2000 and Khan et al., 1997). But it is still a long way for the Bangladeshi people, desperately looking for alternate sources of arsenic-free safe drinking water in their own localities, to go to solve the crisis that already turned into a catastrophe on a vast scale. In Bangladesh about 75 million people are at potential risk and thousands have reached the point of no return (Karim, 2001; SOES and DCH, 2000).

There are several methods available for removal of arsenic from water in large conventional treatment plants. The most commonly used technologies include oxidation, co-precipitation and adsorption onto coagulated flocs, lime treatment, adsorption onto sorptive media, ion exchange resin and membrane techniques (Kohnhorst and Paul, 2000; BAMWSP, 2001; Kartinen and Martin, 1995; Khan et al., 1997; Safiuddin et al., 2003; Wegelin et al., 2000). A detailed review of arsenic removal technologies is presented by Pontius (1990). Shafiuddin and karim (2002) has documented several advances in arsenic removal technologies. In view of the lowering the drinking water standards by USEPA, a review of arsenic removal technologies was made to consider the economic factors involved in implementing lower drinking water standards for arsenic (Chen et al., 1999). Karim (2001) conducted an experiment developing technology for removing arsenic and iron from the ground water of hand tube-well without adding chemicals.

Some of these technologies can be reduced in scale and conveniently be applied at household and community levels for the removal of arsenic from contaminated tube well water. During the last 2-3 years many small scale arsenic removal technologies have been developed, field tested and used under action research programs in Bangladesh and India (Mandal et al., 1996; Zaman, 2000 and Mandal et al., 1998).

The iron arsenic removal unit (IARU) developed by research team aimed to design a filter that is able to significantly reduce arsenic and iron levels to safe, potable levels. In addition, it was tried to provide a field-tested premise for scaling up an appropriate filter technology. By necessity, it is also critical to design a filter that is easy to use and maintain so as to encourage locals to uphold the filter's use. Thus, due to the nature of the project, the promotion, advertising, and ergonomics of the filter is just as important as the functionality of the filter itself.

\section{Methodology}

Initially some basic points were considered for designing the proposed arsenic and iron removal unit. Those were proper size of gravel and sand, internal and outer diameter of Polyvinyl chloride (PVC) pipe, fineness modulus of gravel and sand, simple construction of unit, simple and easy adjustment, made with locally available materials with simple technology, different parts of the machine should be as simple as so that it can be made in local workshop, easy to repair and maintain, cost of unit must be within the reach of people, light in weight and easy to operate. To design this removal unit following sieve size and opening is used (Table 1).

Table 1: Sieve size and opening

\begin{tabular}{|l|c|c|c|c|c|c|c|c|c|}
\hline Sieve size & $3 / 4$ & $1 / 4$ & 4 & 8 & 16 & 30 & 50 & 100 & 200 \\
\hline Opening $(\mathrm{mm})$ & 9.51 & 6.35 & 4.76 & 2.36 & 1.19 & 0.595 & 297 & 149 & 74 \\
\hline
\end{tabular}




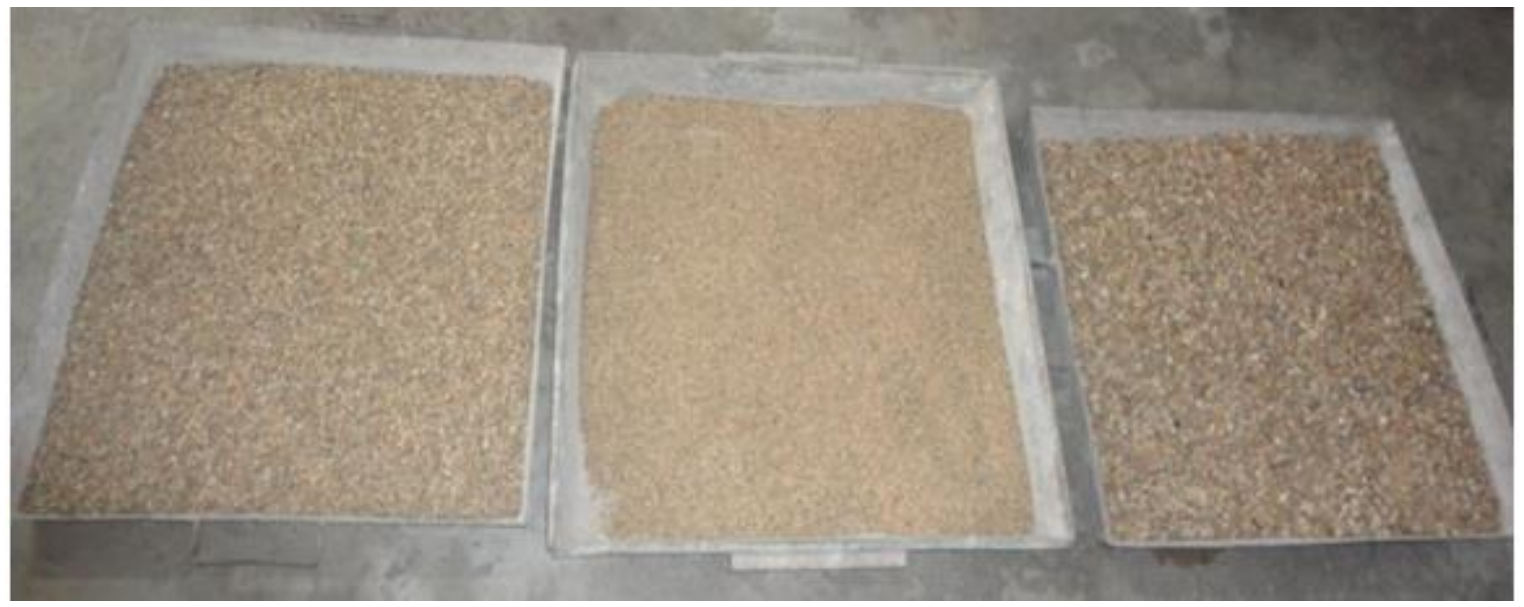

Fig 1: Different types of gravel and sand

A very simple design was made by locally available low cost materials. Materials required to construct this unit were procured from the local market. Most of the parts of the machine were design and fabricated in the Department of Farm Structure, Bangladesh Agricultural University. The major materials required to fabricate the removal unit were follows: PVC pipe (38.1 cm internal diameter), Plastic blind, PVC pipe (5.08cm internal diameter), Hopper, Tape (Inlet and outlet).

To evaluate the proper size of gravel and sand, it is essential to understand on fineness modulus (FM). It is generally defined as an empirical figure obtained by adding the total percentage of the sample of an aggregate retained on each of a specified series of sieves, and dividing the sum by 100. Fineness modulus is generally used to get an idea of how coarse or fine the aggregate is. More fineness modulus value indicates that the aggregate is coarser and small value of fineness modulus indicates that the aggregate is finer. The sieve sizes are $150 \mu, 300 \mu, 600 \mu, 1.18 \mathrm{~mm}, 2.36 \mathrm{~mm}, 4.75 \mathrm{~mm}, 9.5 \mathrm{~mm}$, $19.0 \mathrm{~mm}, 38.1 \mathrm{~mm}$ and larger increasing in the ratio of 2:1. The same value of fineness modulus may be obtained from several different particle size distributions. In general however a smaller value indicates a finer aggregate and higher value a coarser aggregate. Fine aggregates range from a FM of 2.00 to 4.00 , and coarse aggregates smaller than $38.1 \mathrm{~mm}$ range from 6.50 to 8.00. Combinations of fine and coarse aggregates have intermediate values.

Coefficient of Uniformity $\left(\mathrm{C}_{\mathrm{u}}\right)$ is very important to select the particle size of filter medium. It is an indicator of other hydraulic conductivity. A poorly graded soil will have better drainage than a well graded soil because there are more void spaces in a poorly graded soil. Sands with a value of $C_{u}$ of 6 or more, are well graded. Gravels with a value of $\mathrm{C}_{\mathrm{u}}$ of 4 or more, are well graded. The uniformity of a soil is expressed qualitively by term known as uniformity co-efficient, $\mathrm{C}_{\mathrm{u}}$ given by,

$\mathrm{C}_{\mathrm{u}}=\mathrm{D}_{60} / \mathrm{D}_{10}$

Where,

$D_{60}=$ particle size such that $60 \%$ of the soil is finer than this size

$\mathrm{D}_{10}=$ particle size such that $10 \%$ of the soil is finer than this size

Moreover, the general shape of the particle size distribution is described Co- efficient known as Co- efficient of Curveture $\left(\mathrm{C}_{\mathrm{c}}\right)$

$\mathrm{C}_{c}=\left(\mathrm{D}_{30}\right)^{2} /\left(\mathrm{D}_{60} \mathrm{D}_{10}\right)$

Where,

$\mathrm{D}_{30}=$ particle size such that $30 \%$ of the soil is finer than this size

For a well graded soil the value of the Co- efficient of Curveture lies between 1 and 3.

The average diameter of soil particles is also determined from the FM of soil by using the following empirical equation.

$$
\begin{aligned}
& \text { Daverage }=0.0041[2]^{\mathrm{FM}}(\text { inch }) \\
& D_{\text {verage }}=0.10414[2]^{\mathrm{FM}}(\mathrm{mm})
\end{aligned}
$$

Arsenic and iron contaminated water is artificially made in Bangladesh Institute of Nuclear Agriculture (BINA). For this solution 250 microgram arsenic trioxide was collected and tested. $0.1 \mathrm{mg} / \mathrm{L} \mathrm{As} \mathrm{O}_{3}$ was added in $1 \mathrm{~L}$ distilled water. At first arsenic water was prepared. Than $250 \mathrm{ml}$ water was taken into the kitbox. Salfamoic acid and zinc was added into water. Wait until $1 / 2$ an hour and then detected the arsenic limit into water. Iron contaminated water was collected from nearest region of BAU. At first, concentration of iron in water was tested. Then iron contaminated water was passed into the removal unit. Than it is also tested and then result of iron was found. 


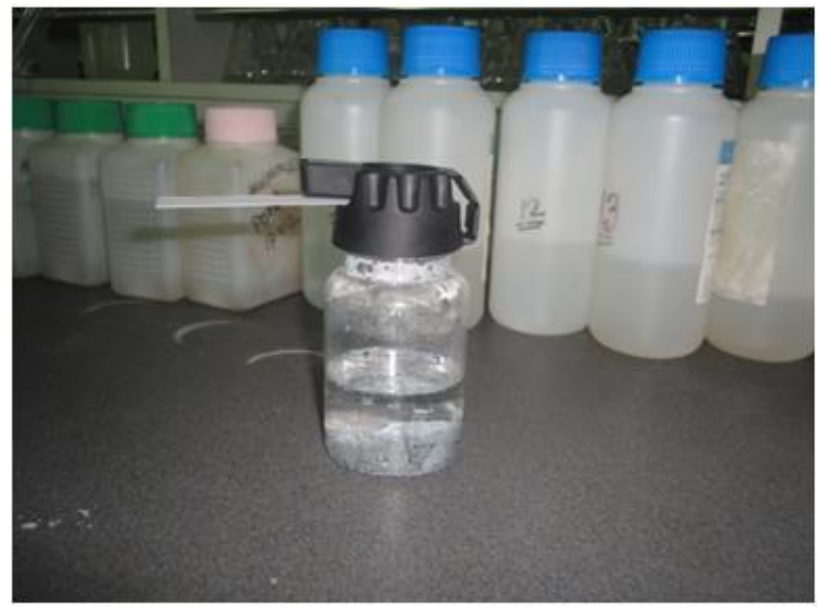

Fig 2: Kit box to detect arsenic

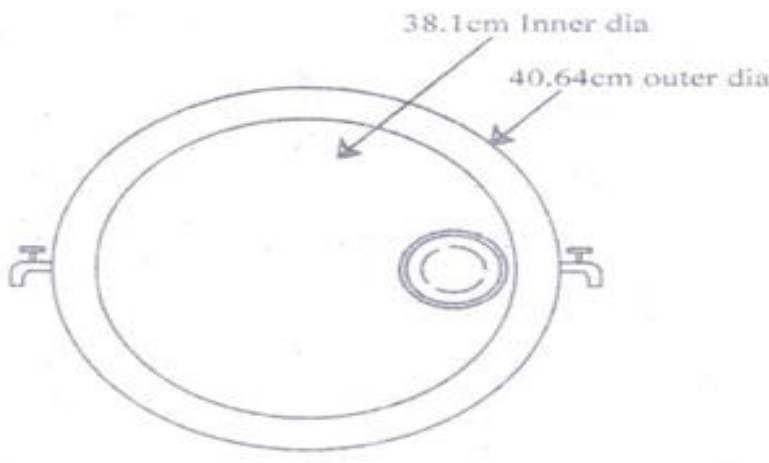

(b)
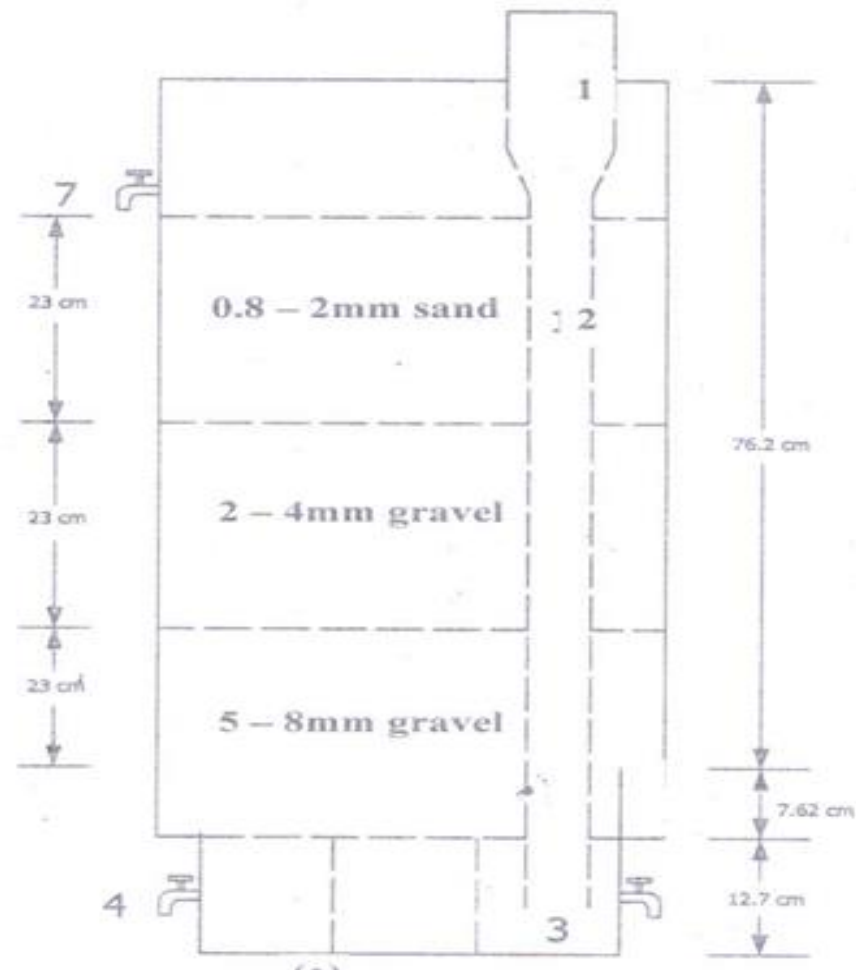

Fig 3: Detection of arsenic

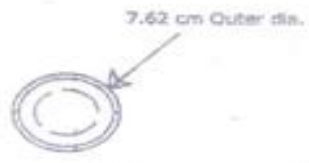

(d)

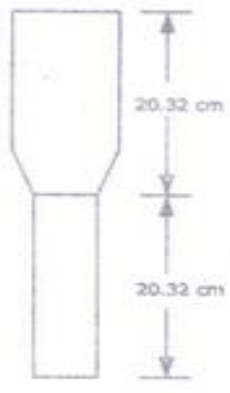

(c)

Fig 4. Arsenic and iron removal unit: (a) Sectional elevation of the whole unit, (b) Plan of the unit, (c) charcoal chamber sectional elevation and (d) Plan of charcoal chamber 
The iron arsenic removal unit $(I A R U)$ was designed by following those components: A small size charcoal chamber whose diameter is $7.62 \mathrm{~cm}$ shown in SL-1, another pipe having $5.02 \mathrm{~cm}$ diameter SL-2, precipitation chamber SL-3, two tape for washout SL-4,Gravel beds SL-5, Sand beds SL-6 and SL-7 is a user tape. The layer of gravel and sand beds are $23 \mathrm{~cm}$. The capacity of this filter is 40 liter water from where 10 liter in pure water. Charcoal chamber was made of PVC pipe at first the PVC pipe was cut according the design and then it was welded as following figure. The height of the chamber was $20.3 \mathrm{~cm}$ and internal diameter $5.08 \mathrm{~cm}$. A slope was developed in the chamber to feed the charcoal in the chamber. The maximum capacity of this chamber is $2 \mathrm{~kg}$.

\section{Results AND Discussion}

By using sieve shaking machine fineness modulus, co-efficient of uniformity, co-efficient of curvature, average diameter of sand, small gravel and gravel were calculated and gradation curves of the medium of removal unit were also prepared. This data was necessary for filtration of arsenic and iron.

\section{Table 2:}

\begin{tabular}{|l|c|c|c|}
\hline & Sand $(0.8-2 \mathrm{~mm})$ & Small gravel $(2-4 \mathrm{~mm})$ & Gravel (5-8mm) \\
\hline Fineness modulus & 4.02 & $5^{\prime} 039$ & 5.702 \\
\hline Co-efficient of Uniformity & 1.42 & 1.58 & 1.75 \\
\hline Co-efficient of Curvature & 1.06 & 1.01 & 1.28 \\
\hline Average Diameter & 1.69 & 3.424 & 5.42 \\
\hline
\end{tabular}

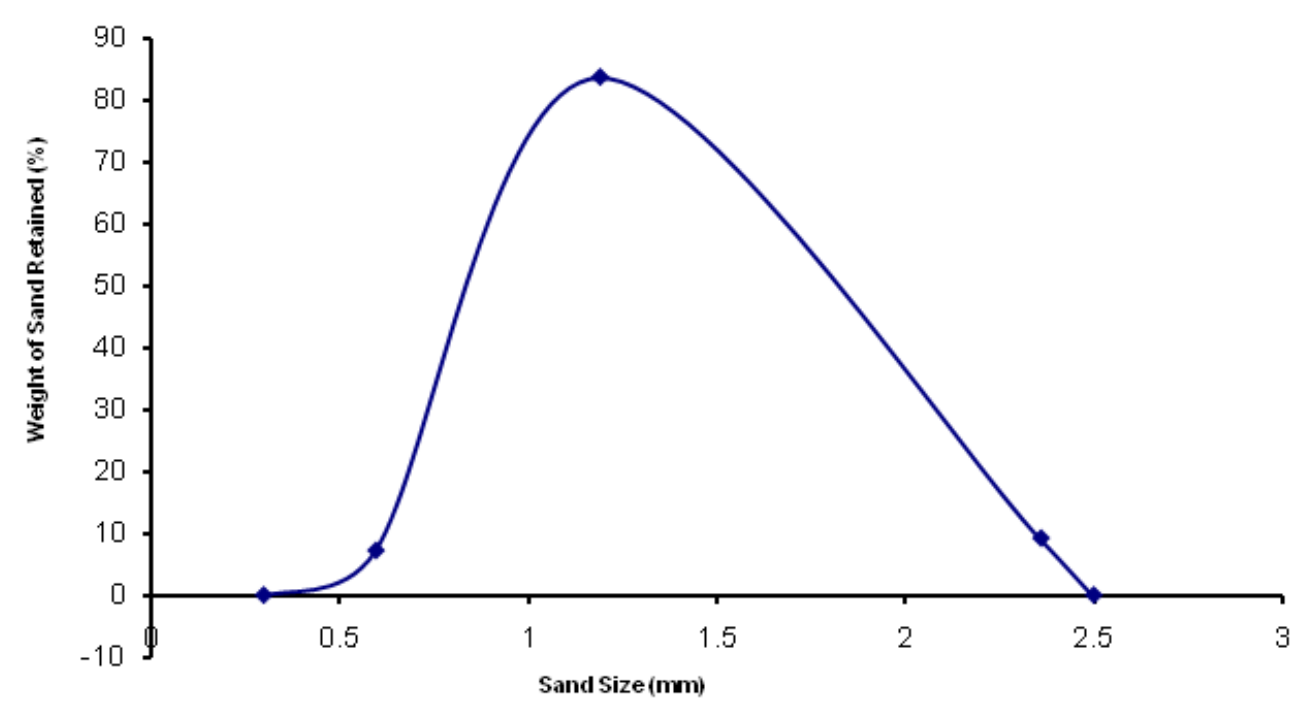

Fig 5: Distribution pattern of sand sizes

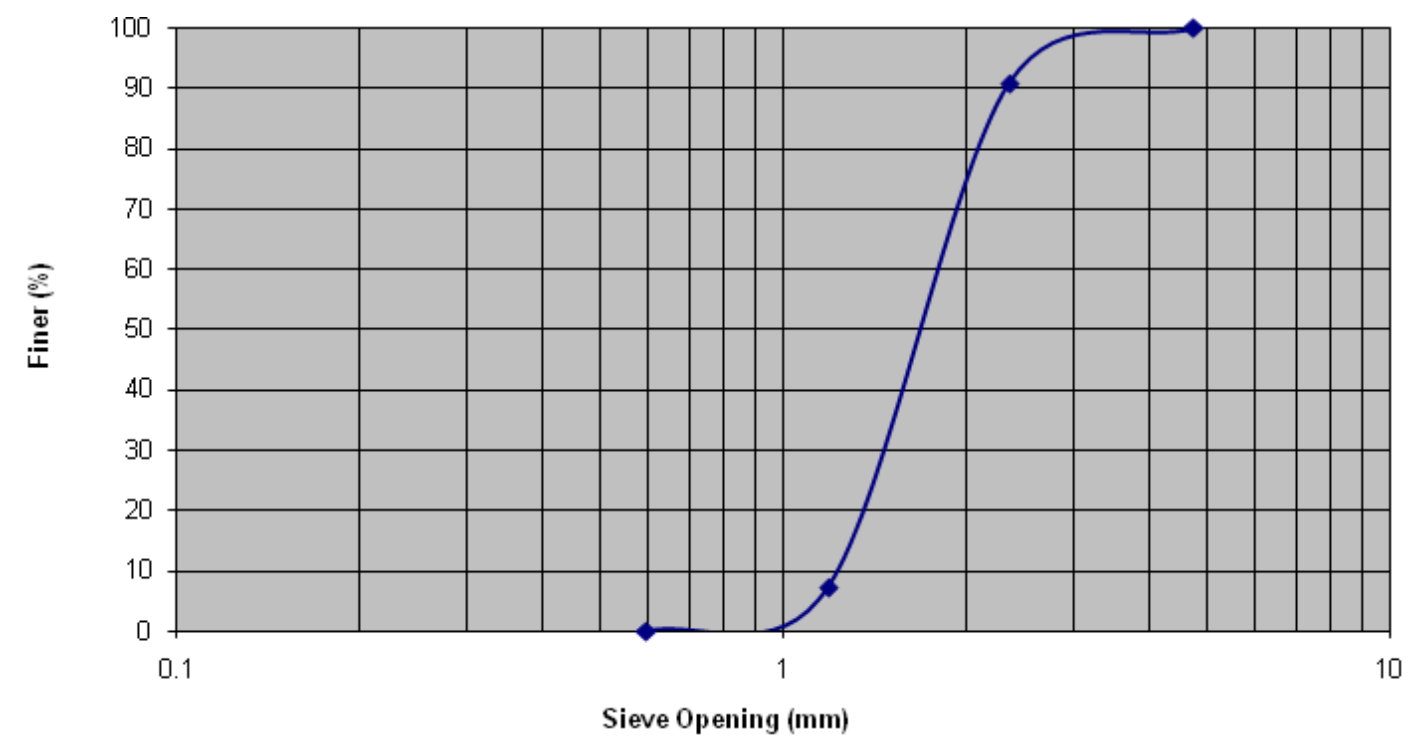

Fig 6: Gradation curve of sand (0.8-2 $\mathrm{mm})$ sizes 
Arsenic and iron contaminated water was added in removal plant. At first water passed in contact with the air and wood charcoal. Then water was passed from $5.08 \mathrm{~cm}$ dia pipe. Oxidation of ferrous iron to ferric iron oxide and arsenite to arsenate occured and absorbed of arsenite compound by wood charcoal takes place. After that, water along with insoluble ferric oxide and arasenate compound as co-precipitants moved down to the precipitation chamber at bottom of the plant through $5.08 \mathrm{~cm}$ diameter PVC pipe. The precipitation chamber also acted as settling tank where water with the precipitants of iron oxide and arsenic remains more than a few hours or one day depending on the frequency of the used of the unit.

Water from the precipitation chamber after leaving some portion of ferric oxide and arsenic moved upward through the holes of the perforated tray. It was a plastic plate of $5.08 \mathrm{~cm}$ tray of diameter $38.1 \mathrm{~cm}$ having 185 perforating holes of diameter less than $2 \mathrm{~mm}$. A plastic bar fixed at the bottom of the perforated tray for supporting it. From the perforated tray, water moved upward through a gravel bed of thickness $23 \mathrm{~cm}$ and then to another gravel bed of thickness $23 \mathrm{~cm}$ and then though as and bed and clear chamber of $23 \mathrm{~cm}$ thick from clean water was being tapped. Diameter, size of the filter beds and the dimension of other parts were shown in Fig. 4. The main body of plant was a PVC pipe of thickness $0.2286 \mathrm{~cm}$. The outer diameter of tank is $38.1 \mathrm{~cm}$. Total height of the main chamber of treatment unit is $96.52 \mathrm{~cm}$. Water before moving upwards left part of iron oxides and arsenate in the precipitation chamber. For this, comparatively pure water moved upwards through the filter beds and as such, filter beds did not get easily clogged and also provided settling time necessary for removal of arsenic.

Water quality should be analyzed before installation of IARU. Arsenic contained in water for effective removal of arsenic by IARU should be equal or less than $0.20 \mathrm{mg} / 1$ if no chemical is used for reducing arsenic to that limit. Iron contain should not less than 0.10 . If the arsenic content less than $0.20 \mathrm{mg} / \mathrm{L}$ the problem of arsenic contamination of all areas of the country is solvable with use of this IARU. After installation and development of the removal unit for three days, water sample on the fourth day of installation should be collected and tested for iron and arsenic content. If it could be assumed that after filtration, Iron and Arsenic contents would meet the criteria for drinking water. During development of IARU water may not be suitable for drinking purpose for high iron and arsenic content. At the end of development of the unit, water sample should be collected and tested in the chemical laboratory for iron as well as arsenic contents. If the results indicate that water is within allowable limit for drinking purpose, it should go for operation for 3 to 4 months but the filter media should be cleaned every month by backwash with opening and closing the flash outs until fresh water comes out from precipitation chamber.

Table 3: Arsenic concentration in the experimental water

\begin{tabular}{|c|c|c|c|c|}
\hline $\begin{array}{c}\text { Input } \\
(\mathrm{mg} / \mathrm{l})\end{array}$ & $\begin{array}{c}\text { Observed } \\
\text { Concentration }(\mathrm{mg} / \mathrm{l})\end{array}$ & $\begin{array}{c}\text { WHO recommended } \\
(\mathrm{mg} / \mathrm{l})\end{array}$ & $\begin{array}{c}\text { Int. standard } \\
(\mathrm{mg} / \mathrm{l})\end{array}$ & $\begin{array}{c}\text { Within Safe } \\
\text { Limit }\end{array}$ \\
\hline 0.05 & 0 & 0.05 & 0.01 & Yes (WHO \& Int. Standard) \\
\hline 0.10 & 0.01 & 0.05 & 0.01 & Yes (WHO \& Int. Standard) \\
\hline 0.15 & 0.025 & 0.05 & 0.01 & Yes (WHO) \\
\hline 0.20 & 0.05 & 0.05 & 0.01 & Yes (WHO) \\
\hline
\end{tabular}

Table 4: Iron concentration in the experimental water

\begin{tabular}{|c|c|c|}
\hline Input (mg/l) & Output (mg/l) & $\%$ reduction of iron \\
\hline 0.18 & 0.10 & 44 \\
\hline 0.1532 & 0.1021 & 33.35 \\
\hline 0.179 & 0.11 & 38.54 \\
\hline 0.133 & 0.09 & 32.33 \\
\hline
\end{tabular}

* Safe limit of Iron in Drinking water is $0.2 \mathrm{mg} / \mathrm{l}$ (WHO)

After installation of the IARU unit water samples for IARU unit have been collected. The collected samples have been chemically analyzed in the BINA. The analyzed results have indicated that water having $1 \mathrm{mg} / 1$ concentration arsenic and $0.1532 \mathrm{mg} / 1$ iron after treatment through IARU unit contained Iron $0.1021 \mathrm{mg} / 1$ and arsenic $0.01 \mathrm{mg} / 1$. Similarly having $0.15 \mathrm{mg} / 1$ arsenic and $0.179 \mathrm{mg} / \mathrm{l}$ iron were treated by IARU unit contained iron $0.11 \mathrm{mg} / 1$ and arsenic $0.025 \mathrm{mg} / \mathrm{l}$.

It may be inferred from the results of the experiment that IARU method of reducing iron content and arsenic content is effective provided that arsenic content of water is equal or less than $0.20 \mathrm{mg} / 1$ and iron content is greater than 0.10 $\mathrm{mg} / \mathrm{l}$. Wood charcoal is effective to reduce the arsenic content, for this charcoal of the IARU unit needs to be replaced by monthly. Washing of the precipitant chamber and back washing of the filter beds by operating the tube well is also required by monthly to have water allowable for drinking purpose. Local mechanics or trained person can do this work 
The effectiveness of IARU for reducing iron and arsenic depends on the proper maintenance. The charcoal of IARU does the functions of absorption of arsenic as well as iron. With the passage of time of about one month (observed in the monitoring the water quality), charcoals get coated with iron oxides, some dissolves with water, so their effectiveness for absorption of arsenic and iron reduces, and consequently arsenic and iron content increase even after filtration. So charcoals need to be replaced. After oxidation, precipitants of iron oxides and arsenates move down into the precipitant chamber. The concentration of iron oxides arsenates increases within one or two months such a level that it starts to move upwards with water through the filter beds on to the clear water chamber. So the precipitants should be removed after opening the flanges. After cleaning the wash out chamber it is to be closed and to fill with water onto the clear water chamber and then open the flange quickly to backwash the sand beds. This process of backwashing the filter media needs to continue until clean water comes out from the wash-out chamber. The effectiveness of sands beds in reducing iron oxides deceases with the passage of time. It's needs to be replaced after one year. Babcock tapes and bucket of the tube well may need to be replaced frequently.

\section{CONCLUSION}

The serious threat to the health of millions of people through consumption of arsenic-rich groundwater in Bangladesh calls for immediate action on various levels. One of these actions is be the development of a low-cost and simple arsenic removal method available to every household. The development of alternative water sources and/or the installation of larger arsenic removal units will take more time due to logistic and financial constraints. Currently existing small-scale arsenic removal procedures require chemicals that are either not easily available and/or affect water taste and odor. On the other hand removal of iron can be achieved on a household scale by cascading the water through the air and allowing the iron oxide particles to settle.

Removal of iron and arsenic as co-precipitants of iron oxide from the arsenic contaminated water is possible by flowing water through wood charcoal to the precipitant chamber and from there upward movement of water through sands and gravel beds. The experiments conducted for removal of iron and arsenic showed positive results. The performance of the removal unit was found satisfactory. The iron content of water reduces by more than 62 percent and arsenic content by 100 percent However, much care should be taken to develop this unit so that it can be operable for a long time. This method of iron and arsenic is cost effective, easily operable and friendly to use. The plant can easily manufactured using locally available materials, technology and the main frame will last more than 30 years with proper maintenance. Maintenance of IARU is also easy and cost is affordable to the users. Removal of Arsenic of IARU depends on concentration. However, the success of IARU depends on the regular cleaning of the precipitant chamber and backwash of sands and gravel beds of the plant after one year more. It needs to take more field performance for the effectiveness of IARU.

\section{REFERENCES}

Allan H.S., Elena O.L. and Mahfuzar, M.R. 2001. Contamination of drinking water by arsenic in Bangladesh: a health hazard. The daily star, 22th March, 2001, p. 5.

Anawas, H.M., Akaj, J., Mostafa, K.M.G., Safiullah, S. and Tareq S.M. 2002. Eight thousands and five hundreds arsenic patients are identified. Graduate school of science and Technology, Niigata University, Ikarashi 2-no-cho, Niigata 950-2181, Japan.

BAMWSP, DFID and WaterAid Bangladesh (2001), Rapid Assessment of Household Level Arsenic Removal Technologies, Phase-! and Phase-II, Final Report, WS Atkins International Limited.

BGS (British Geological Survey) 1999. Ground water studies of arsenic contamination in Bangladesh, By British geological survey and Mott MacDonald (Uk) for the Government of Bangladesh, Ministry of Local Government, Rural Development and Cooperatives, Department of Public Health Engineering and Department for International Development (Uk).

British Geological Survey (BGS) DPHE. 2000. Ground water studies for arsenic contamination in Bangladesh. phase. 1. British Geological Survey, mott MacDonald Ltd. (UK).

Karim, M.M 2001. Arsenic in groundwater and health problems in Bangladesh. Water Research Oxford. 34:1, 304-310.

Karim, M.M. 2000. Arsenic is listed as a hazardous material and is a suspect carcinogen, Dainichi Consultand Inc., 3-1-2, Yabuta Minami, Gifu 5008384, Japan.

Karim, M.M. 2000. The arsenic contamination in ground water indicate that 52 districts are contaminated, around $80 \%$ of the total area of Bangladesh Dainichi Consultant Inc., 3-1-21. Yabuta minami. Gifu 500-8384, Japan.

Kartinen, E. O. and Martin, C. J. (1995), An overview of arsenic removal processes, J. Desalination, 103, 79-88.

Khan, A.W. and Ahmad S.A. (1997). Arsenic in Drinking Water, Health Effects and Management: Training Manual, p. 47 Dhaka. Department of Occupational and Environment Health, NIPSOM.

Khan, A.W. and Alimed, S.A. and Hadi, S.A. (1997). Groundwater arsenic calamity in Bangladesh and West Bengal (supplementary) article to the ECG 21, ulletin, NIPSOM.

Khan, A.W., Ahmad, S.A., Sayed, M.H.S.U., Hadi, S.A., Khan, M.H., Jalil, M.A., Ahmed, R. and Faruquee, M.H. (1997). Arsenic contamination in ground water and its effect on human health with particular reference to Bangladesh. Journal of Preventive \& Social Medicine (JOPSOM) 16, 6573. 
Khan, M.A.H, (1993), Environmental Aspects of Surface Water Development Projects, In: Environment and Development in Bangladesh, (Rahaman et al. edited), University Press Limited.

Kohnhorst, A. and Paul, P. (2000), Testing simple arsenic removal methods, In: Water, Sanitation and Hygiene: Challenges of the Millennium, Pre-prints of the 26 WEDC Conference, Dhaka, Bangladesh., 177-181.

Mandal, B. K., Samanta, G., choudhury, T. R., Dhar, R. K. Biswas, B. K., Chanda, C. R., Saha, k. C. and chakraborti, D. 1998. Three years study on Deganga, one of the sixty one arsenic affected blocks in eight districts of west Bengal, India-A macro level study. Presented in international conference on arsenic pollution of ground- water in Bangladesh. 8-12 Feb., 1998, Dhaka abstr. p. 48.

Mandal, B.K., Choudhury, T.R., Samanta G., Basu, G.K., Chowdhury P.P., Chanda, C.R., Lodh, D., Karan. N.K., Dhar, R.K., Tamili, D.K., Das, D., Saha, K.C. and Chakraborti, D. 1996. Arsenic in ground water in seven districts of West Bengal, India-the biggest arsenic calamity in the world. Curr Sci. 70,976-86.

Pierce, M.L. and Moore, C.B. (1982), Adsorption of Arsenite and Arsenate on amorphous iron hydroxide, Water Resources, 16, $1247-1253$.

Pontius, F.W.(Ed.),1990, Water Quality Treatment: a handbook of community water supplies, American Water Works Association, McGraw-Hill, New York.

Safiuddin, M., Karim, M.M., Murphy, T. and Guo, J. 2003. Water resources management in the remediation of ground water arsenic contamination in Bangladesh. Aquatic Arsenic Toxicity and Treatment. 1-17.

Shafiuddin, M. and karim, M.M. 2002. Arsenic contamination of ground water in Bangladesh Alternative options for safe water. The Bangladesh observer, $1^{\text {th }}$ may, 2002, p.5.

SOES and DCH (2000), Groundwater Arsenic Contamination in Bangladesh, A. Summary of Field Survey from August 1995 to February, 2000: B. Twenty Seven Days Detailed Field Survey Information from April 1999 to February 2000, April.

USEPA.1975. Federal Register. United states Environmental Protection Age, icy. 40. (248): 59566-59588.

Wegelin, M., Gechter, D., Hug, S., Mahmud, A., Motaleb, A. (2000), SORAS-a simple arsenic removal process (http:/ / phys4.harvard.edu/ wilson/mitigation/SORAS_Paper.html).

WHO.1978. International standards for Drinking water. World Health Organization of United Nations, Geneva, Switzerland.

World Health Organization (WHO). 1993. Guidelines for drinking water quality. 2nd edn. Vol. 1. Re commendations, WHO, Geneva. pp. 174.

Zaman, M,W., Rahman, M.M. and zakir., MR 1999. Assessment of grinderies and surface water pollution in some irrig-ited area of Nowabgonj, BAUES Res. Progress, Bangladesh agricultural University, Mymensingh- 2202, Bangladesh. 10: 48- 57.

Zaman, M.W. 2000. Environmental impacts of ground water abstraction in Barind Area. Component B: Water quality and agroecology. Paper Presented at the annual workshop of ARMP contract Research BARC, Dhaka, Bangladesh. 3 April, 2000. 